\title{
Continuous automated ventilation heat recovery efficiency performance assessment using building monitoring system
}

\author{
Tuule Mall Kull ${ }^{1}$, Alo Mikola ${ }^{1, *}$, Andres Tukia ${ }^{1}$, Ahmet Köse $^{2,3}$, Eduard Petlenkov ${ }^{2}$, Martin Thalfeldt ${ }^{1}$ \\ ${ }^{1}$ Nearly Zero Energy Buildings Research Group, Department of Civil Engineering and Architecture, Tallinn University \\ of Technology, 19086 Tallinn, Estonia \\ ${ }^{2}$ Centre for Intelligent Systems, Department of Computer Systems, Tallinn University of Technology, 19086 Tallinn, Estonia \\ ${ }^{3} \mathrm{R} 8$ Technologies company, Tallinn 11415, Estonia
}

\begin{abstract}
The performance of ventilation heat recovery has high impact to the total energy consumption of modern buildings and its sub-optimal performance results in a remarkable energy penalty. There are several issues, which can significantly affect the heat recovery efficiency such as the inaccuracy of sensors, errors in control systems, mechanical defects and incorrect setting of the system. In addition, the direct comparison of the designed and measured heat recovery efficiency is not necessarily meaningful due to varying boundary conditions e.g. mass flow rates. The main focus of this paper is to develop and demonstrate a simple automated method for monitoring the heat recovery efficiency of ventilation units using building monitoring system (BMS). As the supply and extract air mass flows and temperatures may differ from the calculated initial design parameters, the proposed solution is to analyse the heat recovery efficiency using the number of transfer unit (NTU) method. With this method the efficiency is always calculated by the limiting mass flow, meaning that the warm exhaust air can not transfer more energy to the cold supply air than it is able to contain. As a result, the NTU method gives us the possibility to continuously compare the result to the temperature efficiency declared by the producer of the unit. The developed method demonstrated that the application of NTU method enables identifying sub-optimal performance of ventilation heat recovery, which would not have been revealed by direct comparison of temperature efficiencies. In some cases, low measured temperature efficiency was associated with problems not connected to the heat recovery heat exchanger. The method also enabled to estimate the additional heating costs due to the decreased heat recovery efficiency.
\end{abstract}

\section{Introduction}

The performance of ventilation heat recovery (HR) has high impact to the total energy consumption of modern buildings [1]. To save energy in ventilation systems heat recovery using heat exchangers are installed. The most common way to recover the heat in ventilation systems is using the passive heat recovery systems which mainly include flat plate heat exchangers, heat pipe exchangers, run around heat exchangers and rotary wheel heat exchangers [2]. The design of more efficient ventilation systems and units will lead to a reduction in energy demand of buildings [3] but if these systems are not monitored, there is not sufficient information about the real performance of these systems [4]. Modern highefficiency heat recovery systems that ensure the temperature efficiency above $85 \%$ cover the significant part of the heating energy demand of the ventilation systems [5]. It means that the correct design and accurate operation of the heat exchanger of the air handling unit (AHU) plays the most important role in optimizing the energy consumption [6]. Misevičiūte et al. have even stated that the importance of ventilation heat exchangers has increased to the level where the classical methods used in heat exchanger design and analysis are no longer able to provide systems to use energy in an effective way [7]. It possible to conclude that automated method for monitoring the heat recovery efficiency of ventilation units using BMS can solve this problem [8].

There are several issues, which can significantly affect the heat recovery efficiency such as the inaccuracy of sensors, errors in control systems, mechanical defects, air leakages in components and incorrect setting of the system. The supply and extract airflows specified in the design may vary in real operation. For example Hamid et al. [9] made field measurements with clean add dirty heat exchangers; the study show an average increase in the pressure drop by $12 \%$ and decrease in the thermal exchange efficiency by $8.1 \%$. If the increase of the pressure drop in filters or in other components of AHUs are not compensated by the increase in fan speed, the airflows in ventilation units are decreasing [10]. One of the most common reason for the change in supply-air-to-extract-air flow balance is frost formation in plate heat exchangers [11], [12]. If the effective frost protection measures are not taken into use, the pressure drop on the exhaust side of the plate heat exchanger will increase [13].

* Corresponding author: alo.mikola@taltech.ee 
During practical performance of ventilation systems, a number of different types of problems can occur. Javier et al. [14] have proposed that one way to save the energy in ventilation systems is to use the dynamic monitoring through Supervisory Control And Data Acquisition. Prouzeau et al. have pointed out that the current Building Management Systems (BMS) do not allow efficient visualisation of the measured data, which means that even if the data is measured, it is not possible to use its full potential [15]. A user friendly BMS enables to perform a long term monitoring of the AHUs and reduce the energy consumption through the development of better control algorithms [4].

To determine if the heat exchanger is operating effectively, it is possible to compare the measured temperature efficiency to the data that is stated in technical specification of this ventilation unit. At the same time, the direct comparison of the designed and measured heat recovery efficiency is not necessarily meaningful due to varying boundary conditions. To solve the problem of comparison of the heat recovery efficiency the widely known solution is to use Effectiveness of Heat Exchanger-Number of Heat Transfer Unit ( $\varepsilon$-NTU) method [16]. Studies have shown that this method is suitable for the assessment of the thermal performance of counter and crossflow heat [17], [18]. With this method, the efficiency is always calculated by the limiting mass flow, meaning that the warm exhaust air cannot transfer more energy to the cold supply air than it is able to contain [19]. As a result, the NTU method gives us the possibility to continuously compare the result to the temperature efficiency declared by the producer of the unit. The negative side of the simplified NTU method is the fact that this method is not taking into account the influence of latent heat and condensation of water vapour in exhaust side of heat exchanger [20]. As the relative humidity in extract and supply airflows is not measured in practice, then it is not possible to consider this. At the same time, the temperature efficiency, which is calculated according to temperature measurement results inside the heat exchanger, is always higher than the actual sensible temperature efficiency that do not include the condensation of water vapour in heat exchanger. What is more, the comparison is still not meaningful when the heat recovery is not working at full load.

The aim of this work is to find a way to analyse the heat recovery efficiency in buildings with BMS system for the situation when the airflows are not at their design values. The analysis should enable finding faults in the system, although not yet diagnose them.

\section{Methods}

\subsection{Research objects and data acquisition}

In this paper, BMS data trends are the basis for the fault detection and diagnostics of HR units. Manager of the data is a company called R8 Technologies, which gathers and transforms the data into 15-min time steps. In this paper, 17 AHUs are analysed from four buildings
(A, B, C, and D). Building B is located in Finland, the rest in Estonia. While the rest of these buildings were built in the 2010s, the building A and its HVAC systems date to 2004 with major reconstruction in 2014. Table 1 shows the main usage of each building and the length of the gathered datasets.

Building $\mathrm{B}$ is a garage of a supermarket and all its units have design temperature set points at $12{ }^{\circ} \mathrm{C}$ (actual temperature set point $T_{\text {set }}$ at $15^{\circ} \mathrm{C}$ ). Building A's units have been designed for $18{ }^{\circ} \mathrm{C}$ supply temperature, but units $\mathrm{A} 1$ and $\mathrm{A} 4$ are operated at set points of 15 and 16 ${ }^{\circ} \mathrm{C}$. All other units service indoor areas with set points 19 to $21{ }^{\circ} \mathrm{C}$. This and other technical and design data that is essential for this paper, was collected from the building managers and is shown in Table 2.

All chosen AHUs in these buildings include a heat recovery unit with either rotary-, plate-, or run-around coil (RAC) heat exchanger. Efficiency of these heat exchangers is described by the supply side temperature ratio declared according to standard EN 308 [21]. This definition was chosen as the representative declared efficiency while being clearly defined and available for most units. Moreover, EN 308 defines a conservative estimate of efficiency as measured for dry conditions. For building B, only design temperatures where available and the EN 308's efficiency was calculated. Nominal (nom.) flows are the design volumetric airflows for the supply (SUP) and return (RET) sides.

Table 2 lists only one airflow of units where the values for SUP and RET sides are equal.

The data points gathered from BMS for each AHU are shown in

Table 3. The measurement apparatus was the typical equipment used in AHUs, not scientific calibrated devices.

\subsection{Data cleaning and initial filtering}

The periods when AHUs are switched off were not of interest for this work. All but $\mathrm{C} 1$ units are working periodically, i.e., these are switched off during nights, office units also during weekends. Unit $\mathrm{C} 1$ is constantly in use as is common for residential buildings. To eliminate data at nonworking times, either the main switch information or, in the case of building $\mathrm{D}$, a volume flow limit of $0.3 \mathrm{~m}^{3} / \mathrm{s}$ was applied. Data for $\varepsilon_{B M S}$ is not available in unit $\mathrm{C} 1, T_{\text {exhaust }}$ is missing in all units of building $\mathrm{B}$.

\subsection{Fault detection criteria}

\subsubsection{Finding limiting values}

Detecting AHU HR faults, the most obvious is to compare the efficiency estimated from the measured values to the declared efficiency. As mentioned in Section 1, the comparability has to be guaranteed through recalculation if the supply and return airflows are not equal. The method applied in this paper is clarified in Section 2.4.2. 
However, such comparison can be done only when the heat recovery state is correctly $100 \%$ (or close to it, in this work states over $95 \%$ are used) and not high due to a mistake. To classify all possible situations, filters were applied to the data to be confident that the comparison is reasonable where applied. The filters are defined in section 2.3.2.

It is clear that HR should not be working $100 \%$ when it is too warm outside. While the supply temperature has a clear cut-off level at the setpoint, the outdoor temperature does not have such a clear limit. However, from the temperature ratio equation for the supply side [21]:

$$
\varepsilon_{T, S U P}=\frac{T_{\text {supply }}-T_{\text {out }}}{T_{\text {extract }}-T_{\text {out }}}
$$

we can derive that if some declared temperature ratio holds $\left(\varepsilon_{T, S U P}=\varepsilon_{d}\right)$ then the supply temperature should be:

$$
T_{\text {supply }}=\varepsilon_{d} \cdot T_{\text {extract }}+T_{\text {out }} \cdot\left(1-\varepsilon_{d}\right)
$$

where $\varepsilon_{d}$ is the declared temperature ratio and the temperatures were defined in

Table 3. The way to find a suitable declared value is shown in Section 2.4. If $T_{\text {supply }}<T_{\text {set }}$, we can derive from Eq. ( 2 that the outdoor temperature has a limit at $T_{\text {out,limit }}$ :

$$
T_{\text {out }}<\frac{T_{\text {set }}-\varepsilon_{d} \cdot T_{\text {extract }}}{1-\varepsilon_{d}}=T_{\text {out }, \text { limit }}
$$

As in some situations, this limit value can obtain unrealistic values, we limit it to minimum and maximum measured outdoor temperatures across all units. In most cases, $T_{\text {out,limit }}$ will be lower than $T_{\text {set }}$. However, for rare situations, we take into account that the outdoor temperature should also be below $T_{\text {set }}$ when the comparison of efficiencies is allowed. Therefore, to be applied for filtering, we define two limits:

$$
\begin{gathered}
T_{\text {out }, \text { low }}=\min \left(T_{\text {out }, \text { limit }}, T_{\text {set }}\right) \\
T_{\text {out }, \text { high }}=\max \left(T_{\text {out }, \text { limit }}, T_{\text {set }}\right)
\end{gathered}
$$

Table 1. Main usage and data span for each building

\begin{tabular}{|c|c|c|c|c|}
\hline & Usage type & $\begin{array}{c}\text { Duration } \\
\text { (months) }\end{array}$ & Start & Stop \\
\hline A & Supermarket & 13 & $2019-01$ & $2020-01$ \\
\hline B & Garage & 10 & $2019-07$ & $2020-05$ \\
\hline C & Multi-family & 12 & $2019-01$ & $2019-12$ \\
\hline D & Office & 4.5 & $2020-09$ & $2021-01$ \\
\hline
\end{tabular}

\begin{tabular}{|c|c|c|}
\hline Name & Unit & Description \\
\hline$T_{\text {out }}$ & ${ }^{\circ} \mathrm{C}$ & $\begin{array}{c}\text { Outdoor air temperature } \\
\text { measured on building façade }\end{array}$ \\
\hline$T_{\text {supply }}$ & ${ }^{\circ} \mathrm{C}$ & $\begin{array}{l}\text { Supply air temperature } \\
\text { measured after HR but before } \\
\text { heating and cooling coils on } \\
\text { supply side }\end{array}$ \\
\hline$T_{\text {supply,withCoil }}$ & ${ }^{\circ} \mathrm{C}$ & $\begin{array}{l}\text { Supply air temperature to the } \\
\text { rooms }\end{array}$ \\
\hline$T_{\text {extract }}$ & ${ }^{\circ} \mathrm{C}$ & $\begin{array}{l}\text { Return air temperature extracted } \\
\text { from the rooms }\end{array}$ \\
\hline$T_{\text {exhaust }}$ & ${ }^{\circ} \mathrm{C}$ & $\begin{array}{c}\text { Exhaust air temperature } \\
\text { measured after HR on return } \\
\text { side }\end{array}$ \\
\hline$\dot{V}_{S U P}$ & $\mathrm{~m}^{3} / \mathrm{s}$ & Volume flow on supply side \\
\hline$\dot{V}_{R E T}$ & $\mathrm{~m}^{3} / \mathrm{s}$ & Volume flow on return side \\
\hline state $_{H R}$ & $\%$ & $\begin{array}{c}\text { State of the HR: } \\
\text { rotation speed for rotary / } \\
\text { damper valve position for plate / } \\
\text { valve position for RAC } \\
\text { heat exchanger }\end{array}$ \\
\hline$\varepsilon_{B M S}$ & $\%$ & $\begin{array}{l}\text { HR efficiency, only used to } \\
\text { check, which temperature ratio } \\
\text { is used in BMS }\end{array}$ \\
\hline
\end{tabular}

Table 2. AHU data, the first letter of AHU name is the building

\begin{tabular}{|c|c|c|c|c|}
\hline AHU & $\begin{array}{c}\mathbf{T}_{\text {set }} \\
{\left[{ }^{\mathbf{}} \mathbf{C}\right]}\end{array}$ & $\begin{array}{c}\text { HR } \\
\text { type }\end{array}$ & $\begin{array}{c}\text { Temp. } \\
\text { ratio } \\
\mathbf{E N ~ 3 0 8}\end{array}$ & $\begin{array}{c}\text { Nom. airflows } \\
\text { SUP/RET } \\
{\left[\mathbf{m}^{3} / \mathbf{s}\right]}\end{array}$ \\
\hline A1 & 15 & Rotary & 0.777 & $7.5 / 7.3$ \\
\hline A2 & 20 & Rotary & 0.787 & 7.5 \\
\hline A3 & 20 & Rotary & 0.676 & $7.8 / 6$ \\
\hline A4 & 16 & RAC & 0.302 & $3.2 / 2$ \\
\hline A5 & 19 & RAC & 0.359 & $1.3 / 1$ \\
\hline A6 & 21 & RAC & 0.389 & $2.8 / 2.3$ \\
\hline B1 & 15 & Rotary & 0.447 & 8 \\
\hline B2 & 15 & Rotary & 0.447 & 8 \\
\hline B3 & 15 & Rotary & 0.447 & 8 \\
\hline B4 & 15 & Rotary & 0.447 & 8 \\
\hline B5 & 15 & Rotary & 0.447 & 8 \\
\hline B6 & 15 & Rotary & 0.447 & 8 \\
\hline C1 & 21 & Plate & 0.796 & 1.2 \\
\hline D1 & 21 & Plate & 0.700 & 2.75 \\
\hline D2 & 21 & Plate & 0.700 & 2.16 \\
\hline D3 & 20 & Rotary & 0.830 & 5.2 \\
\hline D4 & 20 & Rotary & 0.810 & 4.72 \\
\hline
\end{tabular}

Table 3. Gathered data trends from BMS

\subsubsection{Defining filters}

Based on the supply and outdoor temperatures as well as HR state values, data filters were defined. The filters are shown in Table 4.

First of all, the filter F1 is defined to include the data where the comparison of efficiencies is possible. Therefore, most of the following analysis is based on 
data that is defined by F1 conditions: the supply temperature (before the heating coil) has to be below the setpoint, the outdoor temperature has to be below the limiting temperature defined by Eq. ( 3 and HR state has to be at least $95 \%$.

An automatic control system is changing the temperature setpoints in the buildings at hand and these setpoints are not available at all times. Therefore, a default setpoint level that is often followed is applied, which is also shown in Table 2 for each AHU. This leads to some situations when the setpoint is actually slightly different than taken into account.

When the setpoint is higher than the default level, we classify some of the data that should be below $T_{\text {set }}$ as being above $T_{\text {set }}$ and according to HR state, it falls under filter F5 or F6 together with overheating and warm period situations where actually no HR is needed. When the setpoint is lower than the default level, we classify the warm period or overheating situations under filters F1 through F4 dependent on outdoor temperature and HR state.

Filters other than F1 enable initial fault detection. For example, filters F2, F4, and F5 show problems. However, the diagnosis of these faults would need some further analysis, which is out of scope for this paper. Filters F7 and F8 highlight missing data.

\subsubsection{Fault test}

At times when HR state is correctly over $95 \%$ (F1), we can detect the optimality error in the heat exchanger's work if the realized efficiency $\left(\varepsilon_{r}\right)$ is lower than the potential efficiency. This fault can be detected but the reason cannot be diagnosed based on only this data. Often in practice, such comparison is done without any recalculations based on supply side temperature ratio and EN 308 declared value (BMS method). This would result in some faults left undetected by BMS and some warnings rising where these are not valid.

To clarify this problem, a fault test was defined. The fault test was applied to all timesteps and we were comparing two methods. The result of the test is positive if the given method detects a fault in the system and negative if a fault is not detected. Comparing two methods, we have four possible outcomes of the test: both positive, both negative, method 1 positive and method 2 negative, and vice versa.

We are comparing the NTU method with the BMS method. NTU method re-calculates the benchmark for unbalanced airflows and the process is shown in Section 2.4. Possible fault test outcomes for BMS method and NTU method are shown in

Table 5. As BMS method is the widely used one, the test results are combined with test result labels assessing whether the result given by BMS is correct according to NTU method (true) or not (false).

It is clear that an unfound fault (NTU positive, BMS negative, fault label false negative) can cause expenses whether through higher than expected energy use or resulting in more serious malfunction occurring later. However, a warning rising when no problem actually has occurred (NTU negative, BMS positive, fault label false positive) can result in time and money spent by the maintenance company. It is clear that these are edge cases and when everything is very clearly fine, both test results would be negative (fault label true negative) and positive if something is clearly off (fault label true positive).

For BMS, $\varepsilon_{r}$ is the supply side temperature ratio as given in Eq. (1, for most units also equal to $\varepsilon_{B M S}$, and $\varepsilon_{d}$ is equal to $\varepsilon_{T, E N 308}$, the declared temperature ratio according to EN 308. In the case of building A, the BMS actually visualizes the return side temperature ratio, not the supply side one. However, the comparison was still calculated against the supply side temperature ratio for our further analysis. For NTU method $\varepsilon_{r}$ is the same but $\varepsilon_{d}$ is the supply side temperature ratio benchmark calculated from Eq. (12.

Table 4. Data filter definitions combined with logical AND functions ( $T_{\text {supply }}$ is without heating after the HR)

\begin{tabular}{|c|c|c|c|c|}
\hline$T_{\text {supply }}$ & $T_{\text {out }}$ & state $_{H R}$ & \multicolumn{2}{|c|}{$\begin{array}{c}\text { Filter label and } \\
\text { description }\end{array}$} \\
\hline$<T_{s e t}$ & $<T_{\text {out }, \text { low }}$ & $\geq 95 \%$ & $\mathrm{~F} 1$ & $\begin{array}{c}\text { state }_{H R} \geq \\
95 \%, \text { correctly }\end{array}$ \\
\hline$<T_{\text {set }}$ & $<T_{\text {out }, \text { low }}$ & $<95 \%$ & F2 & $\begin{array}{c}\text { state }_{H R}< \\
95 \%, \\
\text { incorrectly }\end{array}$ \\
\hline$<T_{\text {set }}$ & $\begin{array}{l}\geq T_{\text {out,low }} \\
<T_{\text {out }, \text { high }}\end{array}$ & $\begin{array}{l}\text { Not } \\
\text { NaN }\end{array}$ & F3 & $\begin{array}{c}\text { state }_{H R}< \\
95 \% \text { allowed }\end{array}$ \\
\hline$<T_{\text {set }}$ & $\geq T_{\text {out }, \text { high }}$ & $\begin{array}{l}\text { Not } \\
\text { NaN }\end{array}$ & F4 & Problem \\
\hline$>=$ Tset & Not $\mathrm{NaN}$ & $\geq 5 \%$ & F5 & Overheating \\
\hline$>=$ Tset & Not $\mathrm{NaN}$ & $<5 \%$ & F6 & Warm period \\
\hline Any & $\mathrm{NaN}$ & $\begin{array}{l}\text { Not } \\
\text { NaN }\end{array}$ & F7 & $\begin{array}{c}T_{\text {out }} \text { not } \\
\text { available }\end{array}$ \\
\hline Any & Any & $\mathrm{NaN}$ & F8 & $\begin{array}{l}\text { state }_{H R} \text { not } \\
\text { available }\end{array}$ \\
\hline
\end{tabular}

Table 5. Possible fault test results for BMS and NTU methods comparing efficiency levels

\begin{tabular}{|c|c|c|c|c|}
\hline BMS & $\begin{array}{c}\text { Fault test } \\
\text { result }\end{array}$ & NTU & $\begin{array}{c}\text { Fault test } \\
\text { result }\end{array}$ & $\begin{array}{c}\text { Fault } \\
\text { label }\end{array}$ \\
\hline$\varepsilon_{d} \leq \varepsilon_{r}$ & negative & $\varepsilon_{d}>\varepsilon_{r}$ & positive & $\begin{array}{c}\text { False } \\
\text { negative }\end{array}$ \\
\hline$\varepsilon_{d} \leq \varepsilon_{r}$ & negative & $\varepsilon_{d} \leq \varepsilon_{r}$ & negative & $\begin{array}{c}\text { True } \\
\text { negative }\end{array}$ \\
\hline$\varepsilon_{d}>\varepsilon_{r}$ & positive & $\varepsilon_{d} \leq \varepsilon_{r}$ & negative & $\begin{array}{c}\text { False } \\
\text { positive }\end{array}$ \\
\hline$\varepsilon_{d}>\varepsilon_{r}$ & positive & $\varepsilon_{d}>\varepsilon_{r}$ & positive & $\begin{array}{c}\text { True } \\
\text { positive }\end{array}$ \\
\hline
\end{tabular}

\subsection{Calculations for redefining the benchmark}

\subsubsection{Effectiveness and efficiency}

In the most traditional approach, BMS visualizes one temperature ratio for a HR unit, the temperature ratio for the supply side (Eq. (1). To detect faults, this is sometimes continuously compared to the declared efficiency value, but mostly it is just used as an indicator for times when it is severely off the expected value. To 
be clear, temperature ratio and efficiency $\varepsilon_{T}=\varepsilon$ are used as synonyms. Effectiveness $\varepsilon_{E}$ is the ratio of heat flows, at unequal mass flows this is not equal to efficiency.

Using the definition, the effectiveness could be calculated as follows [22]:

$$
\varepsilon_{E}=\frac{q}{q_{\max }}
$$

The maximum heat flow in the denominator is for both the supply and the return side [22]:

$$
q_{\max }=C_{\min }\left(T_{\text {extract }}-T_{\text {out }}\right)
$$

$C_{\text {min }}$ is the minimum of the heat capacity rates of the supply and return flows [22]:

$$
C_{\min }=\min \left[\dot{m}_{S U P} c_{p, S U P}, \dot{m}_{R E T} c_{p, R E T}\right]
$$

Here $\dot{m}$ is mass flow and $c_{p}$ is the specific heat capacity of the fluid. Mass flows were calculated from volume flows and air density. For density calculation Eq. (9 was used [22], [23]:

$$
\rho(t)=1 \frac{\mathrm{kg}}{\mathrm{m}^{3}} \cdot 353 \mathrm{~K} /(273.15 \mathrm{~K}+t)
$$

where $t$, the air temperature in ${ }^{\circ} \mathrm{C}$ for the given point was taken into account where possible. As $T_{\text {exhaust }}$ is missing for all units in building B, $T_{\text {out }}$ was used for the density calculation instead. However, the return side temperature ratio could not be estimated still as the temperature ratio for the return side is [21]:

$$
\varepsilon_{T, R E T}=\frac{T_{\text {extract }}-T_{\text {exhaust }}}{T_{\text {extract }}-T_{\text {out }}}
$$

The nominator in Eq. (6 would include the multiplication of the respective temperature ratio nominator (from Eq. (1 and Eq. (10), and the respective heat capacity rate (e.g. $\dot{m}_{S U P} c_{p, S U P}\left(T_{\text {supply }}-T_{\text {out }}\right)$ for the supply side).

In our data, the temperatures are between $-20^{\circ} \mathrm{C}$ and $+40{ }^{\circ} \mathrm{C}$ at all times. In this range of temperature and pressure around atmospheric pressure, the specific heat capacity stays close to constant and therefore the $c_{p}$-s cancel out. With balanced airflows, the temperature ratios are equal to the heat flow ratios as the mass flows cancel out as well.

For unbalanced airflows, it is often suggested to use the heat flow rates for efficiency estimation. However, the heat flow ratio could become larger than 1 for the side with larger mass flow, not representing the efficiency any more. The nominator would be multiplied with the mass flow at the observed side and the denominator with the minimum of two mass flows. Therefore, one of the effectiveness values would not differ from the temperature ratio while the other would be larger.

When the temperature ratio is known, the effectiveness can be also calculated as:

$$
\varepsilon_{E, S U P}=\frac{C_{S U P}\left(T_{\text {supply }}-T_{\text {out }}\right)}{C_{\min }\left(T_{\text {extract }}-T_{\text {out }}\right)}=\frac{C_{S U P}}{C_{\min }} \varepsilon_{T, S U P}
$$

Here, we can reduce the $\varepsilon_{E}$ by the ratio of the corresponding heat capacity rates $\left(C_{\min } / C_{S U P}\right.$ or
$C_{\min } / C_{R E T}$ respectively). For the supply side it would be:

$$
\varepsilon_{T, S U P}=\frac{C_{\min }}{C_{S U P}} \varepsilon_{E, S U P}
$$

When the declared effectiveness is known, this would enable getting a declared value, which would be comparable to the temperature ratio visualized in BMS.

Unexpectedly, we obtain also an opportunity to not only evaluate the supply side temperature ratio but we similarly also get a benchmark for the return side. As condensation is not taken into account, this has to be applied only carefully. In the ideal case of no condensation and no heat transfer to the ambient, the temperature ratio on the return side would be similar to the supply side. In reality, it is almost always different (often lower) than the supply side efficiency, especially for plate heat exchangers.

\subsubsection{Applying NTU}

To enable continuous fault detection at all airflows, a benchmark that could be compared to the temperature ratio is needed. To get this variable, we use the NTU method. Supply side temperature the AHU producers declare according to EN $308\left(\varepsilon_{T, E N 308}\right)$ and nominal airflows are used as the starting basis. This declared efficiency level is given at dry conditions, which guarantees a conservative benchmark due to almost no condensation effect. This value is mostly given at balanced mass flows $\left(\varepsilon_{T, E N 308}=\varepsilon_{E, E N 308}\right)$ with temperature of $20{ }^{\circ} \mathrm{C}$ used for both sides in calculations so it is also for balanced volume flows. Therefore, it can be and was transformed with NTU method into a benchmark for unbalanced airflows on the basis of general textbooks in the field [22], [23] as follows. Declared NTU was first calculated from the declared temperature ratio assuming balanced mass flows [23]:

$$
N T U_{E N 308}=\frac{\varepsilon_{T, E N 308}}{1-\varepsilon_{T, E N 308}}
$$

If the mass flows are not equal for the design case (units A1, A3, A4, A5, A6), NTU can be calculated for the counterflow heat exchangers as [23]:

$$
N T U_{E N 308}=\frac{1}{C_{r}-1} \ln \left(\frac{\varepsilon_{E, E N 308}-1}{\varepsilon_{E, E N 308} C_{r}-1}\right)
$$

Calculation from $\varepsilon_{T, E N 308}$ to $\varepsilon_{E, E N 308}$ for unbalanced flows is done similarly as in Eq. (11. $C_{r}$ is the ratio of heat capacity rates [23]:

$$
C_{r}=\frac{C_{\min }}{C_{\max }}=\frac{\min \left[\dot{m}_{S U P} c_{p, S U P}, \dot{m}_{R E T} c_{p, R E T}\right]}{\max \left[\dot{m}_{S U P} c_{p, S U P}, \dot{m}_{R E T} c_{p, R E T}\right]}
$$

where $C_{\min }$ and $C_{\max }$ are, respectively, the minimum and maximum of the heat capacity rates of the supply and return flows. Clearly, for a system with balanced mass flows $C_{r}=1$, which is why a different formula has to be used in unbalanced and balanced mass flow cases.

The assumption of counterflow situation in Eq. (14 does not apply to all heat exchangers, but the explanation why this is assumed is shown later with the 
example of Eq. (18. For now, we continue from NTU calculated from Eq. (13 or (14.

NTU describes the potential heat transfer rate as:

$$
N T U=\frac{U A}{C_{\min }}
$$

where $\mathrm{U}$ is the overall heat transfer coefficient and $\mathrm{A}$ is the heat transfer surface area (equal at both sides [23]). Values of NTU should be positive. From here, UA can be calculated for the design case.

To enable the transformation from a balanced situation to unbalanced airflows, we should assume that something in the heat exchanger stays constant. When the airflows do not change much, either NTU or UA could be assumed to be constant. However, to guarantee the applicability for large differences in airflows, NTU is not fixated and UA is assumed to be constant. Of course, in reality, $U$ can vary as well, especially for very low or extremely high airflows, and effective area can vary due to dust, but this is out of the scope of this paper.

Assuming that UA stays constant for both when the airflows are balanced or unbalanced, we could calculate UA from the design situation and then NTU from this UA at any measured $C_{\min }$ from Eq. (16. Then, the declared effectiveness for unbalanced airflows can be calculated from Eq. (17 [22], [23]:

$$
\varepsilon_{E, d}=\frac{1-\exp \left[-N T U\left(1-C_{r}\right)\right]}{1-C_{r} \exp \left[-N T U\left(1-C_{r}\right)\right]}
$$

where measured $C_{r}$ and $N T U$ for measured $C_{\min }$ are applied. This is the effectiveness formula for counterflow heat exchangers and Eq. (14 is the reverse of this. This is practically usable in most cases. However, it could be that in some cases, cross-flow (single pass) form of the formula could be more accurate [23]:

$$
\varepsilon_{E}=1-\exp \left(\frac{N T U^{0.22}}{C_{r}}\left(\exp \left(-C_{r} N T U^{0.78}\right)-1\right)\right)
$$

This and other formulas for effectiveness have been derived for several different types of heat exchangers. However, re-arranging this formula for NTU, like done in Eq. (14 for the counterflow formula, does not result in an explicit solution. That means a numerical estimation of NTU would be needed instead of direct calculation like in Eq. (14, which is not simple enough to apply in BMS. Therefore, the counterflow formula is used for all heat exchangers in this work [18]. However, to quantify the possible error we make with this, the difference of applying these formulas was compared at different NTU and Cr values in Section 3.1.

Using the assumption that UA is constant, we can derive from Eq. (16 that:

$$
N T U=\frac{C_{n o m, \min } \cdot N T U_{E N 308}}{C_{\min }}
$$

When additionally assuming balanced measured airflows, we can derive using Eq. (13 and any $C_{\min }$ that:

$$
\varepsilon_{T}=\varepsilon_{E}=\frac{N T U}{N T U+1}=\frac{N T U_{E N 308}}{N T U_{E N 308}+\frac{C_{\text {min }}}{C_{n o m, \min }}}
$$

Eq. (20 will be used in Section 3.3 to visualize how the airflow effectiveness changes when airflows are different from designed.

In the general case, the NTU from Eq. (19 would be inserted to Eq. (17 and the obtained effectiveness would be translated to the benchmark temperature ratio by applying Eq. (12, or similar equation for the return side. The $N T U_{E N 308}$ for applying in Eq. (19 would be calculated from Eq. (13 or (14 dependent whether the design situation is for balanced or unbalanced airflows. Often the last step of applying Eq. (12 is omitted, which would result in efficiency over $100 \%$ for one side and is therefore not usable.

\subsubsection{Selection software comparison}

To ensure that the methods applied really output reasonable results, Fläkt design software "Acon" was used to compare the resulting efficiencies. Design conditions of $T_{\text {out }}=-20, T_{\text {extract }}=22$ were used, and $c_{p}=1.005$ was assumed. Several cases were tested, as an example, three situations are reported in Table 6 with the results in Table 7. There will be differences between the two as the program additionally takes into account the leakage and condensation effects that we omit in this paper. However, the difference cannot be large for the chosen situations if our approach is working well.

Table 6. Definition of comparison cases in Acon software

\begin{tabular}{|c|c|c|c|}
\hline Situation & $\begin{array}{c}\text { Design } \\
\text { efficiency }\end{array}$ & $\begin{array}{c}\text { Volume flow } \\
\text { design }\left[\mathbf{m}^{3} / \mathbf{s}\right] \\
\text { SUP/RET }\end{array}$ & $\begin{array}{c}\text { Volume flow } \\
\text { test }\left[\mathbf{m}^{3} / \mathbf{s}\right] \\
\text { SUP/RET }\end{array}$ \\
\hline 1 & $82.3 \%$ & 1 & $0.9 / 0.7$ \\
\hline 2 & $82.3 \%$ & 1 & 2 \\
\hline 3 & $82.3 \%$ & 1 & 0.5 \\
\hline
\end{tabular}

\section{Results and discussion}

\subsection{Comparison between cross- and counter- flow effectiveness formulae}

The possible effectiveness values from counterflow and cross-flow formulas Eq. (17) and (18 are calculated for $\mathrm{Cr}$ in between 0 and 1 and NTU in between 0 and 10 . The effectiveness is shown as a separate line for each $\mathrm{Cr}$ value with 0.1 steps in Figure 1. Crossflow is shown in solid and counterflow in dashed lines. Difference of these two is shown in the small surface plot inside the graph. We can see that at high NTU and $\mathrm{Cr}$ the difference can be as high as 10 percent points. Effectiveness for cross-flow units is in all cases lower than for counterflow, which we use further. 


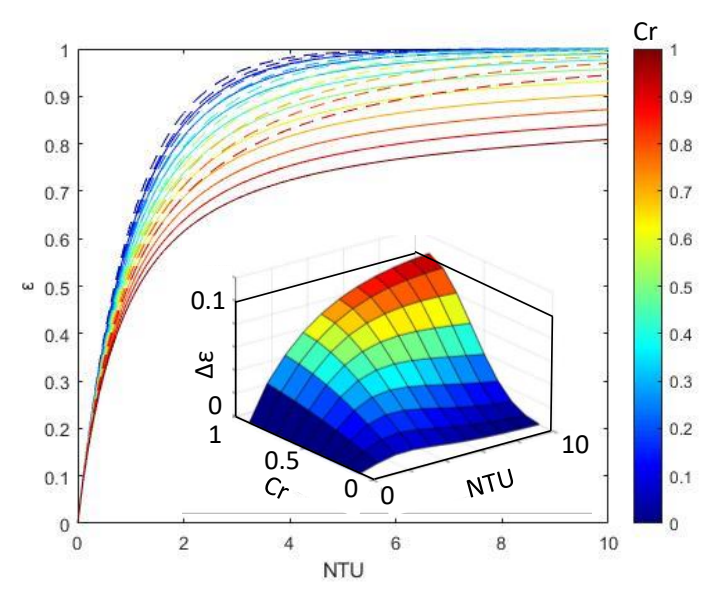

Figure 1. Cross- (solid lines) and counter- (dashed lines) flow effectiveness $(\varepsilon)$ change with rising of NTU and Cr. Surface plot shows difference between the two methods.

\subsection{Comparison with AHU selection software}

Table 7. Acon software and NTU method comparison results

\begin{tabular}{|c|c|c|}
\hline Situation & Fläkt efficiency & Efficiency from NTU \\
\hline 1 & $70.5 \%$ & $72.5 \%$ \\
\hline 2 & $68.0 \%$ & $69.4 \%$ \\
\hline 3 & $89.5 \%$ & $89.9 \%$ \\
\hline
\end{tabular}

Table 7 shows that there is some difference between the Acon software results and the ones calculated according to the NTU method described in Section 2.4. Although, the underlying method for Acon software probably includes also the NTU method. Among the main reasons for the differences, Fläkt supposedly takes into account the condensation effects that NTU method applied in this way does not. NTU method in general includes it, but in many cases, we do not have the data needed for the estimation. Still, the differences are small, varying for the observed cases from 0.4 to $2 \%$. The method adequately handles the increase and decrease from nominal volume flows. The temperature ratios stay below or maximally at $100 \%$ according to the NTU method, which it should as being the efficiency.

\subsection{Influence of airflow difference from design situation on effectiveness}

From the methodology, it is clear that volume flows different from the design situation may change the benchmark. The actually measured volume flow distributions together with nominal value points are shown in Figure 2. We can see that AHUs A1 through A3 and all AHUs in building B operate with significantly lower airflows than designed. AHUs A4 through A6 have highly varying airflows around the designed values and AHUs in building D have two airflow modes, one close to nominal and one slightly lower. This can be explained by a period in 2020 when during night the office units where not shut off but operating at lower airflows to keep the rooms clean from virus.
In Figure 3, the calculated effectiveness values from Eq. (20 are plotted against the ratio $R=C_{\min } / C_{\text {nom,min }}$. The ratio is the multiplier to get the actual mass flow from the design situation. A tendency can be spotted in the measured values (points). Therefore, the theoretical effectiveness value (lines) was calculated for each unit at different $R$ values. However, this calculation is possible in the general case without including temperatures only when we assume balanced airflows. We can see that at $R$ above the grey line (airflows larger than designed) the fit is good. The theoretical situations converge at $R=0$, which would mean no airflow at either the supply or return side or both and is therefore not practical. In the measured points, very low mass flows and therefore low $R$ values are not included in the data. However, the converging can be spotted at around $R=0.2$. Therefore, the fit for the ratios below the grey line is not ideal.

In both Figure 2 and Figure 3, we can see high variability in airflows for building A units. This is mainly caused by the fact that the units and their controllers and sensors are old. However, there is also more data available from these units and the management company has used machine learning based control solutions for a longer period, gradually improving the algorithms.

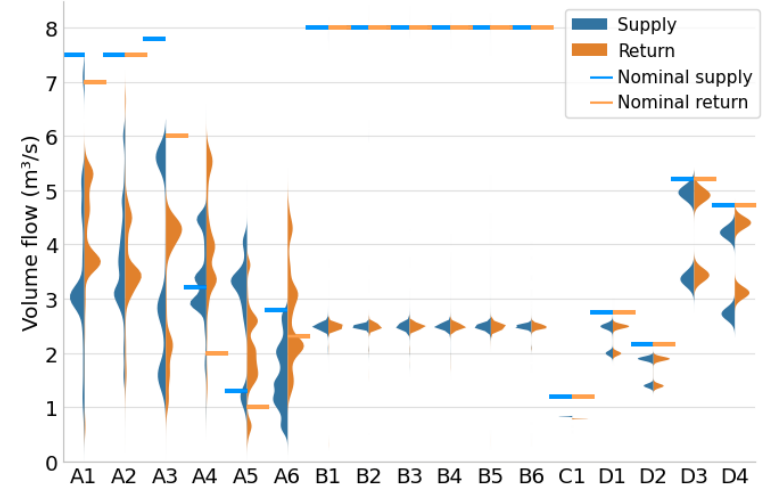

Figure 2. Measured and nominal volume flows for each AHU, measured data distributions from BMS, cut-off below $0.3 \mathrm{~m}^{3} / \mathrm{s}$.

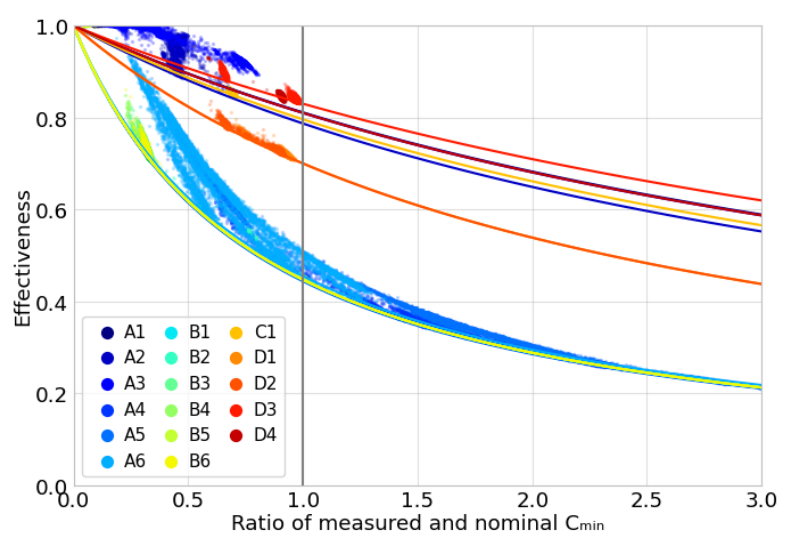

Figure 3. Effectiveness level dependent on ratio of measured and nominal $C_{\min }$ values, scatter points are actually measured values and lines represent the theoretical situation at balanced airflows. 


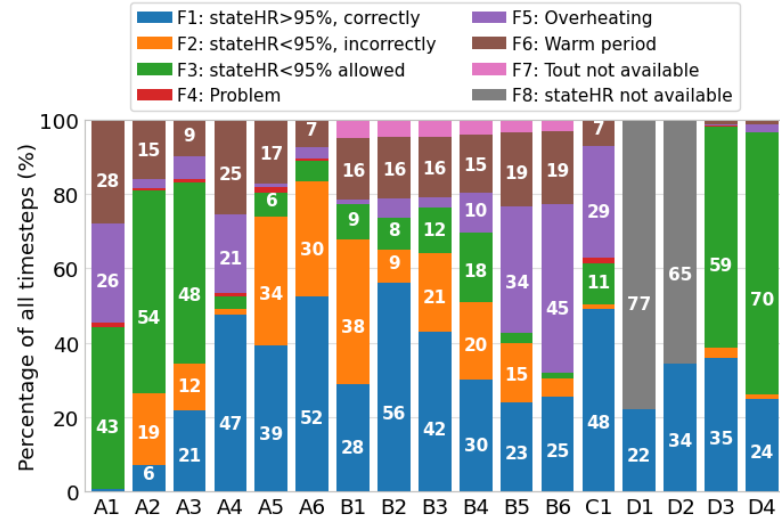

Figure 4. Filtering results according to classifications in Table 4

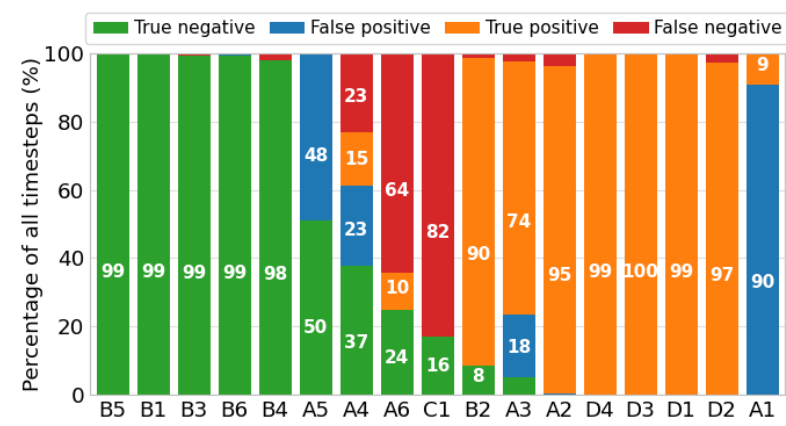

Figure 5. Fault test results: percentage of time AHU spends in each class out of the filtered data, ordered for better readability

\subsection{Filtering results}

The HR is not working at its maximum potential the whole time. It is clear that sometimes this is the wanted behaviour. Figure 4 shows the data filtered by the conditions in Table 4 . The only part we actually analyse is the part where HR state is and should be over $95 \%$. This is shown in the chart in blue and ranges from 0.5 to $56 \%$ of all data depending on the AHU. The $0.5 \%$ still includes around 100 data points.

The datasets include summer periods when heat recovery is correctly not working. Building D has data from September to January and therefore no warm period is included. Building D was integrated to the monitoring system in September, but the bypass damper position data was only included starting from December. That is why most of the data for D1 and D2 are not usable for us. This is generally a big problem that some data is not available.

\subsection{Fault test results}

The fault test results for each unit are shown in Figure 5. The units on x-axis are ordered with mostly true negatives on the left and mostly true positives on the right. Almost half of the units have many true positive values, meaning that there is a fault, which is detected by both the simple and the NTU method. All units in building $\mathrm{D}$ belong here. Moreover, for many units it applies that true negatives dominate where $\mathrm{HR}$ is working fine and both methods show the same. All units in building B belong here, except B2 which has mostly true positives. As the unit itself is very similar to other units in building B, this AHU should be checked for malfunctions.

Four units in the building A appear to have faults according to the simple BMS method, but NTU does not show these faults. These are the blue false positive columns in Figure 5. We can assume that if there is something wrong, the fault is not caused by the HR. Most probably NTU does not show a problem as the airflows are much higher at some timesteps for these units than designed.

There are two units, for which BMS shows no fault, but NTU often reports problems. The difference is quantified in the next section. We can see from Figure 6 that for $\mathrm{C} 1$, the difference is actually very small. If we would also compare the return side here, we would have a lot more problem signals as this is a plate heat exchanger and condensation affects the results often. However, as the condensation effect is not taken into account, it would not be correct.

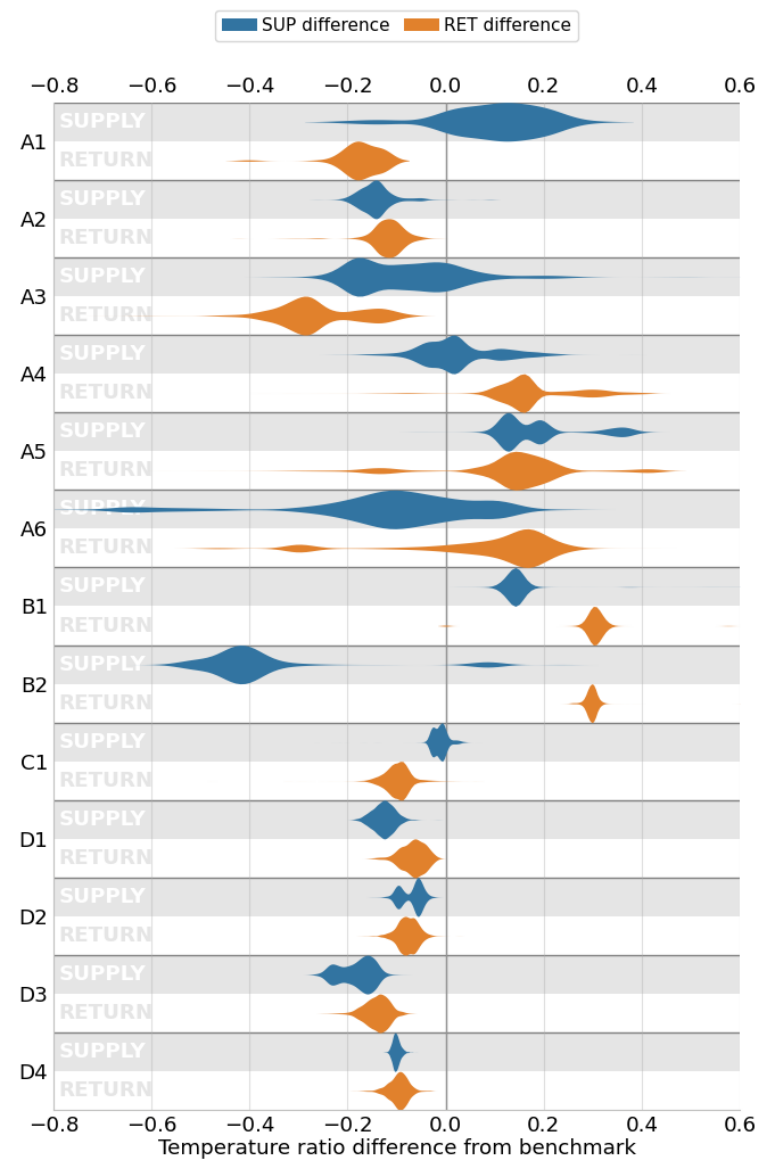

Figure 6. Difference between the temperature ratio and the NTU benchmark, negative means underperforming and positive well-performing situation

\subsection{HR efficiency performance}

The temperature ratio and benchmark differences for each time step for both supply and return sides are summarized in Figure 6. Units B3 through B6 are omitted as the results are very similar to unit B1. 
However, there is a clear difference in unit B2 performance, although it is also similar to the other units in building B. The variability is very large in all units in the building A due to the same effects described in Section 3.3. We can see that in the building A, rotary heat exchangers (A1 to A3) are underperforming while RAC heat exchangers are mostly performing as expected as the benchmark levels for these units are very low. In building B, all AHUs except B2 perform well. $\mathrm{B} 2$ efficiency is on average 40 percentage points lower than expected. In buildings $\mathrm{C}$ and $\mathrm{D}$, all chosen units underperform. It was known that unit D3 was damaged during transport and we can see that its performance is actually 10 percentage points lower than for other units in this building.

\section{Conclusions}

The paper shows that the variation of NTU method is well suitable for continuous performance assessment of the heat recovery efficiency. For the old building A, the variations are large and for some units only a small portion of the data is comparable. Still, the variations also reflect in the benchmark and therefore the method clarifies some situations when the BMS method gives faults. While for other units the variations are much smaller, it also enables to identify problems more clearly. The method enabled us to quantify the lack of efficiency for the unit D3, a unit with known physical faults. Compared to units in the same building the efficiency was 10 percentage points lower. A unit with unknown fault was detected, the unit B2. In future work, the difference in efficiency should be translated to additional cost for the owner and further data filters should be developed to not only detect but also diagnose the faults. The main limitation of this method is its applicability to HR working at full load only. Partial loads are prevailing situations for spring and autumn conditions and a solution to apply same or similar method should be developed in future.

This research was supported by the Estonian Centre of Excellence in Zero Energy and Resource Efficient Smart Buildings and Districts, ZEBE (grant 2014-2020.4.01.150016) funded by the European Regional Development Fund, by the European Commission through the H2020 project Finest Twins (grant No. 856602) and the Estonian Research Council grant (PSG409). This research is also financed by the Archimedes grant named Applied research in smart specialisation growth areas (NUTIKAS, LEP19101) and supported by R8 Technologies.

\section{References}

[1] A. Grzebielec, A. Rusowicz, and A. Ruciński, "Analysis of the performance of the rotary heat exchanger in the real ventilation systems," in 9th International Conference on Environmental Engineering, ICEE 2014, 2014.

[2] Z. Liu, W. Li, Y. Chen, Y. Luo, and L. Zhang, "Review of energy conservation technologies for fresh air supply in zero energy buildings," Applied Thermal Engineering, vol. 148. pp. 544-556, 2019.

[3] D. O'connor, J. K. S. Calautit, and B. R. Hughes, "A review of heat recovery technology for passive ventilation applications," Renewable and Sustainable Energy Reviews, vol. 54. pp. 1481-1493, 2016.

[4] L. Schibuola, M. Scarpa, and C. Tambani, "Performance optimization of a demand controlled ventilation system by long term monitoring," Energy Build., vol. 169, pp. 4857, 2018.

[5] A. Meiss, M. Á. Padilla-Marcos, I. PozaCasado, and A. Álvaro-Tordesillas, "A graphical tool to estimate the air change efficiency in rooms with heat recovery systems," Sustain., vol. 12, no. 3, 2020.

[6] V. Misevičiūtè, K. Valančius, V. Motuzienè, and G. Rynkun, "Analysis of exergy demand for air heating of an air handling unit / Violeta Misevičiūtè, Kęstutis Valančius, Violeta Motuzienė, Genrika Rynkun.," Energy Effic., vol. 10, no. 4, pp. 989-998, 2017.

[7] V. Misevičiūtè, K. Valančius, V. Motuzienè, and G. Rynkun, "Analysis of exergy demand for air heating of an air handling unit," Energy Effic., vol. 10, no. 4, pp. 989-998, 2017.

[8] V. Martinaitis, G. Streckiene, A. Bagdanavicius, and J. Bielskus, "A comparative thermodynamic analysis of air handling units at variable reference temperature," Appl. Therm. Eng., vol. 143, pp. 385-395, 2018.

[9] A. Abdul Hamid, D. Johansson, and M. Lempart, "Determining the impact of air-side cleaning for heat exchangers in ventilation systems," Build. Serv. Eng. Res. Technol., vol. 41, no. 1, pp. 46-59, 2020.

[10] A. Hamburg, K. Kuusk, A. Mikola, and T. Kalamees, "Realisation of energy performance targets of an old apartment building renovated to nZEB," Energy, vol. 194, 2020.

[11] A. Jedlikowski and S. Anisimov, "Analysis of the frost formation and freeze protection with bypass for cross-flow recuperators," Appl. Therm. Eng., vol. 116, pp. 731-765, 2017.

[12] A. Pacak, A. Jedlikowski, D. Pandelidis, and S. Anisimov, "Analysis of freeze protection methods for recuperators used in energy recovery from exhaust air," in E3S Web of Conferences, 2017, vol. 22.

[13] A. Jedlikowski, S. Anisimov, J. Danielewicz, M. Karpuk, and D. Pandelidis, "Frost formation and freeze protection with bypass for counter-flow recuperators," Int. J. Heat Mass Transf., vol. 108, pp. 585-613, 2017.

[14] J. M. Rey-Hernández, S. L. González, J. F. San José-Alonso, A. Tejero-González, E. VelascoGómez, and F. J. Rey-Martínez, "Smart energy management of combined ventilation systems in a nZEB," in E3S Web of Conferences, 2019, 
vol. 111.

[15] A. Prouzeau, M. B. Dharshini, M.

Balasubramaniam, J. Henry, N. Hoang, and T.

Dwyer, "Visual Analytics for Energy

Monitoring in the Context of Building

Management," in 2018 International

Symposium on Big Data Visual and Immersive Analytics, BDVA 2018, 2018.

[16] S. Borjigin, S. Zhang, M. Zeng, Q. Wang, and T. Ma, "Coupling $\varepsilon$-NTU method for thermal design of heat exchanger in cabinet cooling system," Appl. Therm. Eng., vol. 159, 2019.

[17] S. H. Noie, "Investigation of thermal performance of an air-to-air thermosyphon heat exchanger using $\varepsilon$-NTU method," Appl. Therm. Eng., vol. 26, no. 5-6, pp. 559-567, 2006.

[18] H. Jaber and R. L. Webb, "Design of cooling towers by the effectiveness-NTU method," $J$. Heat Transfer, vol. 111, no. 4, pp. 837-843, 1989.

[19] H. A. Navarro and L. C. Cabezas-Gómez, "Effectiveness-ntu computation with a mathematical model for cross-flow heat exchangers," Brazilian J. Chem. Eng., vol. 24, no. 4, pp. 509-521, 2007.

[20] R. Adamovský, D. Adamovský, and D. Herák, "Exergy of heat flows of the air-to-air plate heat exchanger," Res. Agric. Eng., vol. 50, no. No. 4, pp. 130-135, 2018.

[21] European Commitree of Standardization, "EN 308:1997. Heat Exchangers - Test Procedures For Establishinng Performance of Air to Air and Flue Gases Heat Recovery Devices,” 1997.

[22] T. L. Bergman and A. S. Lavine, Fundamentals of Heat and Mass Transfer, 8th editio. Wiley, 2017.

[23] L.-Z. Zhang, Total heat recovery: heat and moisture recovery from ventilation air. New York: Nova Science Publishers, Inc., 2008. 